\title{
DEL GOBERNANTE DIVINO AL DIRIGENTE PATERNO ${ }^{12}$
}

\author{
Miguel Catalán González \\ Universidad CEU Cardenal Herrera
}

\begin{abstract}
RESUMEN
El artículo estudia el argumento mítico y religioso del paternalismo político en virtud del cual la sociedad es hija del gobernante, en especial del monarca. Del mismo modo que el rey en tanto Dios crea a la humanidad desde la nada, también el rey en tanto padre se presenta como su engendrador o fundador. El presente análisis tiene una estructura diacrónica que comienza en el estadio mítico-religioso de los pueblos africanos y de la China clásica, atraviesa la Antigüedad grecorromana y el modelo medieval de la familia como modelo de la sociedad, y termina con la teoría política de John Filmer sobre el origen bíblico de la monarquía.
\end{abstract}

Palabras clave: política; religión; paternalismo; monarquía; Filmer.

\begin{abstract}
The article studies the mythical and religious argument of political paternalism by virtue of which society is the daughter of the ruler, especially the monarch. Just as the king as God creates his people from nothing, so also the king as father presents himself as his begetter or founder. The present analysis has a diachronic structure that begins at the mythical-religious stage of African peoples and classical China, goes through Greco-Roman Antiquity and the medieval model of the family as a pattern of society, and ends with John Filmer's political theory of the biblical origin of the monarchy.
\end{abstract}

Key words: politics; religión; paternalism; monarchy; Filmer.

1 [Durante el proceso de edición de este artículo se produjo el desgraciado fallecimiento de nuestro querido amigo y colaborador Miguel Catalán. Télos quiere rendir homenaje a su obra y pensamiento, a su memoria, publicando aunque sea tristemente de forma póstuma, este trabajo, como siempre fueron sus trabajos, lleno de agudeza y originalidad.]

2 [Recibido el 14/05/2019. Aceptado para su publicación: 24/05/2019.] 
Gracias a ti, César, el buey vaga por el prado y los barcos navegan sin temor

Virgilio

Para toda propaganda de la sumisión elaborada por la clase rectora, tan fuerte es la tentación de convertir al jerarca en una suerte de Dios como hacer de él un Padre benevolente, pues el pueblo siempre se mostró receptivo a ambas patrañas. Estas dos fórmulas complementarias, la santa mentira y la noble mentira, proceden, en efecto, de la necesidad humana de encontrar, sea allá en el Cielo o acá en el Trono, un progenitor simbólico que sustituya en nuestra vida adulta a quien nos cuidó durante la infancia. Ahondando en su tesis del miedo como origen de la religión, Sigmund Freud advirtió que el adulto inerme ante los pavorosos poderes de la naturaleza tiene las mismas urgencias psíquicas que un niño necesitado de protección; en pos de la confianza en sí mismo y la tranquilidad de ánimo no puede sino configurar en su mente un fantasma paterno de irresistible fuerza que sea a la vez protector y temible. Este enérgico impulso filial fue pronto aprovechado por los mandatarios. El gobernante sería el progenitor divino tan buscado, o bien un vástago o elegido suyo, pero asimismo, siguiendo la lógica afectiva del desamparo de los súbditos al crecer, un padre humano para la vida política.

Sea como Dios Eterno en la tierra o como Padre Vitalicio en el trono, la patria deviene hija del progenitor trascendente y este se convierte en padre de la patria. La teodicea del poder pone la realidad patas arriba como si volviera un calcetín del revés. Desde luego que el gobernante es hijo, y no padre, de la sociedad que lo ve nacer y le hace crecer; pero el mito político afirma justo lo contrario: que la sociedad es hija del jerarca. Del mismo modo que el rey en tanto dios crea a su pueblo, también el rey en tanto padre se presenta como su engendrador o fundador. En el mundo primitivo, un Estado típico del África oriental y meridional responde a la impronta del fundador mítico revisada por Lucy Mair: 
"A un linaje determinado se le reconoce el derecho a proporcionar el gobernante, y este derecho se apoya en una leyenda (la carta mítica, tal como la denomina Malinowski), que relaciona a los miembros de este linaje con el origen de la nación. Se mantiene la creencia de que el antepasado fundador fue el primero en llegar al país sobre el que gobierna el linaje, surgiendo de la tierra o de un río, o descendiendo del cielo, o bien que condujo a su pueblo desde algún otro sitio venciendo en el camino, milagrosamente, diversas dificultades."3

La realeza que aprovecha el impulso mítico del pueblo lleva su linaje al remoto pasado hasta convertir al antepasado del monarca en fundador de la polis, en creador de la nación. Los ciudadanos le deben, en un sentido profundo, su existencia. Tal identidad forjada por los mitos antiguos y las ideologías modernas, resuena en la voz de origen germánico "Atila", que significa "padre", y en la voz rusa batiushka, "padrecito" o "pequeño padre”, aplicada por la tradición a los zares.

En tanto Padre proveedor del pan de cada día bendecido por Dios, el Rey es no solo quien lo reparte entre sus fieles súbditos, sino el que baja del cielo para vivificar a sus criaturas. Encarnación del Padre Eterno dueño de toda propiedad y digno de toda alabanza, ya en la antigua China el rey era quien, según la propaganda gubernamental, hacía que "corriera el agua de los ríos". La leyenda interesada daba así la vuelta al esfuerzo cotidiano de los industriosos pescadores, a quienes transforma con la lengua del mito en meros agraciados por la generosidad de quien, en realidad, vivía a su costa. El labriego esquilmado por los tributos reales creía que la suerte de la cosecha dependía de la voluntad del rey. En consecuencia, la parte que le arrebataban era sólo una porción del bien que el rey y sus secuaces habían creado; la otra porción se la quedaba el hombre de la gleba no sin dar las gracias a su dios y a su señor. Los labradores aran, siembran y cultivan la tierra, pero es el monarca quien crea la cosecha de la nada con su poder y voluntad divinos. ${ }^{4}$ Hasta la humanidad del súbdito es producto de la esplendidez del jerarca. El emperador Yu, fundador de la primera dinastía china, la de Xia (XXI a.C.-XVI a.C.), introdujo según cierta historia legendaria las medidas para controlar las inundaciones, y un refrán chino se lo agradece con estas palabras: "De no

3 Lucy Mair, Introducción a la antropología social, Madrid: Alianza, 1978, pág. 127.

4 Max Weber, La ética económica de las religiones universales, pág. 292, en Ensayos sobre sociología de la religión I, Madrid: Santillana, 1998, págs. 233-579. 
ser por Yu, seríamos todos peces". ${ }^{5}$ Si el rey es el padre de la nación, entonces sus tierras y propiedades le pertenecen por derecho natural. La ética confuciana que a partir del siglo $\mathrm{V}$ a. C. forjó la ideología conservadora del poder con el dominio de la dinastía Han sobre el país exige que el gobernante sancionado por el cielo actúe como un padre amoroso que derrama bendiciones entre sus hijos: "Sólo proporciona verdadera satisfacción al pueblo”, dicta el viejo Libro de las Canciones glosado por Confucio, "el príncipe que actúa como un padre y como una madre". ${ }^{6}$ En una enseñanza oral atribuida a Confucio encontramos asimismo la siguiente admonición: "Profesad a vuestro padre el mismo amor que tenéis a vuestra madre, y el respeto que alimentáis hacia el príncipe, y serviréis al príncipe con piedad filial, y seréis sumisos a vuestros superiores y dóciles ciudadanos. Peca el que se rebela contra el rey porque su corazón no posee la piedad filial que hace fácil la obediencia”?

Que los súbditos se conviertan en hijos es, desde luego, la mejor noticia posible para el dueño del cetro.

El poder soberano sobre la tierra del emperador en Egipto también tiene su base psicológica en el hecho de que alimenta a sus súbditos con las riquezas procedentes de la crecida anual del Gran Río, debidas a su función creadora como hijo del Dios munificente. ${ }^{8}$ Qué otra cosa puede hacer el hijo sino expresarle su gratitud.

En diversas formas del Estado tradicional, la tierra y sus frutos son propiedad del Jefe o el Rey. Este, como el dueño de la hacienda al compartir cuanto tiene con sus vástagos, presta o dona graciosamente la tierra a sus vasallos para que la cultiven a cambio de una parte del producto del trabajo. Ante nosotros se alza la imponente realidad del Estado patrimonial, el cual se atribuye arteramente a sí mismo la creación de los propios terrenos cultivables, sea por concesión particular divina o merced a la administración hidráulica, como si antes no se la hubiera arrebatado a los campesinos por la fuerza y luego por la ley y la administración de justicia. Según el relato sacro, el Estado posee por voluntad o aquiescencia divina, pues, a los hombres y las

5 Gordon Cheers (ed.), Mitología, Barcelona: RBA, 2005, pág. 352.

6 Confucio, Los cuatro libros clásicos, Primer libro. Ta-Hio, X, 3, Barcelona: Bruguera, 1978, pág. 60.

7 César Cantú, Historia universal, vol. V, Madrid: Establecimiento de Francisco de Paula Mellado, 1847, págs. 122-123.

8 Ian Shaw (ed.), Historia del Antiguo Egipto, Madrid: La Esfera de los Libros, 2007, pág. 373 . 
tierras; $\mathrm{y}$ si concede el usufructo de las segundas a los primeros es por un acto de munificencia real: las regalías. La realidad histórica suele ser la contraria; en origen, pero también durante el ocaso del sistema feudal que dio paso al capitalismo, la tierra que araban los campesinos les fue enajenada a la fuerza por los señores que portaban las armas y dictaban las leyes.

El parentesco entre el gobernante divino y el paterno no se ha extinguido. Una de las definiciones del cielo ha sido la de aquella "mansión de Dios" donde el Padre Eterno ocupa el centro luminoso del espacio doméstico. En la era cristiana, los fieles infantes llaman al pontífice "Santo Padre" en tanto heredero de Cristo en su ministerio pastoral, y al clérigo, simplemente, "padre" (pater). Aunque, como veremos más adelante, esa longeva institución política que es la Iglesia Católica utilizó con éxito notable el recurso retórico a la maternidad vicaria en la figura de la clemente Virgen María, no renunció por ello a la totipotente paternidad vicaria. En primer lugar en la figura del heredero de Cristo, el santo pontífice llamado Papa o Santo Padre. Del mismo modo que la Virgen María es madre de todos los cristianos en tanto genitora del Cristo fundador de la fe, el Papa es el padre de los hombres en tanto sucesor de Pedro, el heredero del fundador. La Iglesia propone a sus fieles ahijados y, en especial, a los gobernantes laicos, una obediencia doble: en tanto criaturas, deben acatar la voluntad de Dios; en tanto vástagos, la del Santo Padre. Ampliando el símil del filósofo Tommaso Campanella, el emperador medieval debía obediencia al Papa porque César debió la misma obediencia a Pedro que el hijo debe al padre: Cesare usi a Pietro, la reverenza dovuta dal figlio al Padre. ${ }^{9}$ Gracias a una dilatación de sentido muy útil para reforzar la obediencia debida de los parroquianos, hay que llamar padre no solo al Papa, sino también a cualquier ministro de la Iglesia. Ya San Pablo se llama a sí mismo "padre" de sus feligreses en la Primera Carta a los Corintios al predicarles el Evangelio, y no de pasada o metafóricamente, sino pretendiendo haberlos engendrado realmente en el espíritu: "No os escribo estas cosas para avergonzaros, sino para amonestaros como a hijos míos queridos. Pues aunque hayáis tenido diez mil pedagogos en Cristo, no habéis tenido muchos padres. He sido yo quien, por el Evangelio, os engendré en el Hijo Jesús. Os rue-

9 Cit. en Moisés González García, “prólogo”, pág. 18, en Tommaso Campanella, La política, Madrid: Alianza, 1991, págs. 9-62. 
go, pues, que seáis mis imitadores". ${ }^{10}$ A fin de obtener la obediencia indiscutida a la patria potestad, Pablo se impone como padre de la feligresía indócil de la iglesia de Corinto. Del mismo modo se dirigen en ocasiones los párrocos y predicadores a sus parroquianos y oyentes: "Hijos míos...".

Las mentes infantiles y las mentalidades primitivas subliman en la divinidad la figura a la vez donante y censora del progenitor. Como todo lo que se proyecta al cielo es devuelto a la tierra, la figura luminosa de ese monarca doméstico enviado al cielo que es el padre se convertirá, al bajar de vuelta a la tierra, en el Dios terreno. Los hombres públicos favorecidos por esta vieja creencia nunca dejaron de aprovecharla para sus intereses de gobierno. Si en la sublimación primigenia había que acatar la voluntad de Nuestro Señor de los cielos al modo en que seguimos dócilmente las órdenes de nuestro padre terreno, en la legitimación de vuelta hay que acatar la voluntad del gobernante vitalicio al modo en que hemos cumplido las órdenes del Padre Eterno.

La leyenda del mito confluye con la lección de la historia: el jefe es digno de obediencia en tanto padre consagrado. Nietzsche señala esta transición de la santa mentira a la noble mentira que ha permitido a los dominantes mantener el cetro de la realeza una vez cayó al suelo la tiara sacerdotal. Si por la santa mentira la multitud plebeya debe obedecer al noble gobernante porque actúa en la tierra en nombre de Dios, o, al menos, con el beneplácito divino, por la noble mentira cabe acatar sus decretos porque es un gran padre de la ciudad o Padre de la Patria. La figura del Pater patriae, sea en su versión oficial como título concedido por los órganos de gobierno desde el Senado romano o bien en su versión meramente retórica, se encuentra a medio camino entre el pater familias o cabeza de familia terrenal y el Pater noster in coelis o padre celestial de la humanidad.

\section{LA MONARQUía}

La atribución de virtudes divinas al mandatario adquirió muy pronto la forma de monarquía. El gobernante único representa, en tanto el mónos personalizado del arjé, la figura correspondiente al padre único y al Dios único, o, al menos, hegemónico en un panteón plural. En el cristianismo del Medievo la poderosa imagen del padre de fa- 
milia se proyecta sobre cualquier autoridad: "La familia, marco fundamental de las relaciones sociales, cuya imagen gobierna también las formas de pensamiento, queda impresa en toda representación del poder, sea el de Dios, el del rey, el del obispo, el del padre abad, el del señor del castillo sobre sus vasallos, el del terrateniente sobre sus arrendatarios" ${ }^{11}$

La Iglesia de Roma, monarquía arquetípica, nos brinda la figura eminente de esta ideología que reduce la plebe a gentío pecuario necesitado de un guía providente. A partir de la división que hace Tertuliano de la sociedad cristiana entre el "orden" (la clase sacerdotal) y la "plebe” (el laicado), la Iglesia desplegará una estructura binaria ordenada por Dios que reserva el orden y la jerarquía para el clericato: son los "prelados", los "rectores", todos aquellos supraordinados que dirigen, enseñan y pastorean al pueblo subordinado los asuntos del común. ${ }^{12}$ El pontífice, el soberano, el príncipe aparecen así como padres prolíficos y amorosos cuyos hijos forman la suma de hermanos que componen la Iglesia o la nación.

La raíz indoeuropea *poter- significa tanto padre como jefe de clan. En latín, pater quiere decir propiamente padre de familia, en tanto el padre biológico se queda como simple genitor. Para ser padre no basta con engendrar un hijo, sino que también hay que hacerse responsable de su crianza. Quedan restos semánticos comunitarios de pater tanto en la palabra "patrón" (jefe de empresa) como en "padrino" (padre vicario o, también, jefe mafioso). Por su parte, y en tanto invocación afectuosa al padre, el término "papa” también significa en diversas culturas jefe o caudillo. Los indígenas de México llamaban "papa” a sus jefes, como recogen los invasores españoles: "E allí vinieron luego los caciques y papas de los pueblos de Guaxocingo"13, escribe Bernal Díaz del Castillo de camino a la capital mexica. El mismo vocablo emplean los indígenas de las islas Samoa para nombrar a sus caciques: papa haka’ki. ${ }^{14}$ "Papa" tiene en diversas lenguas un matiz de afecto y dependencia infantil que persiste en la voz castellana "papilla”. En el mismo sentido, la voz aramea y hebrea "abba", padre, también es el

11 Georges Duby, Les trois ordres de l’imaginaire du féodalisme, pág. 626, en Féodalité, París: Gallimard, 1996, págs. 450-825.

12 Ibidem, pág. 536.

13 Bernal Díaz del Castillo, Historia verdadera de la conquista de la Nueva Espana, vol. I, Madrid: Sarpe, 1985, pág. 333.

14 Robert S. Williamson, The Social and Political Systems of Central Polynesia, vol. II, Cambridge: Cambridge University Press, 1924, pág. 362. 
origen del término "abad”, jefe de la comunidad monástica. El vocablo "Papa" referido al Santo Pontífice procede del griego Pappas, padre; aplicado a los obispos en los primeros siglos del cristianismo, más adelante concentrará toda su dignidad en el obispo de Roma.

El monarca y el déspota en el territorio que domina, así como el padre en la casa que dirige, no son elegidos por sus subordinados. La monarquía procede de la jefatura, y esta de la autoridad paterna a través de la figura del déspota. La relación intrínseca entre monarquía, despotismo y paternalismo político viene a oponerse al complejo de república, democracia e igualitarismo. El ser humano se engrandece en la democracia y se empequeñece en el despotismo, explica bellamente Millon-Delsol:

"Bajo el poder despótico, en efecto, el hombre es considerado como un esclavo o como un niño: tal es la consecuencia de la asimilación histórica del gobierno despótico al gobierno doméstico o familiar. Es tratado como un ser irresponsable, no solo incapaz de dirigir la comunidad a que pertenece, sino incapaz de tomar iniciativa en sus propios asuntos, que son administrados por el funcionario del príncipe."15

El déspota es aquel señor que trata al pueblo con la misma autoridad absoluta e indiscutida que el amo trata a su esclavo y el padre de familia a su mujer e hijos. Es un poder familiar y doméstico llevado al terreno social, el del jefe militar, dictador, rey oriental. Como ya vimos en su lugar, el despotes griego no es en su origen oriental sino el padre de familia, más adelante el señor del clan o el jefe guerrero. Al pasar a la cultura romana, el despotes dará lugar al dominus latino que en el siglo X reivindicará el poder del Princeps romano sobre el universo gracias a su título de dominus mundi.

Opuesta frontalmente a esta tradición despótica basada en la familia que llegó de Oriente, la escuela democrática de pensamiento político que despunta en Grecia y se expone en Aristóteles defiende la pluralidad de intereses de los ciudadanos El gobierno es solo una parte de esa pluralidad, y otros miembros de la polis pueden albergar creencias o valores distintos que merecen voz y voto. Hannah Arendt se hace eco de esta virtud política aristotélica al señalar que es un error basar la política en la célula familiar: "Las familias se fundan como albergue y fortificación en un mundo inhóspito y extraño en el que uno desea establecer parentescos. Este deseo conduce a la

15 Chantal Millon-Delsol, Essai sur le pouvoir occidental, París: PUF, 1985, pág. 60. 
perversión fundamental de lo político, porque, a través de la introducción del concepto de parentesco, suprime, o más bien pierde, la cualidad fundamental de la pluralidad". ${ }^{16}$ Frente a la igualdad y pluralidad democráticas de la época clásica griega compactadas en la voz isonomía, que será una igualdad bajo la ley de todos los ciudadanos, hasta los de mayor alcurnia, la igualdad bajo el monarca imperial mesopotámico o iranio era "familiar", pues venía marcada por la nivelación de la muchedumbre bajo la voluntad soberana de un monarca que se situaba por encima de la ley. La igualdad de los hijos en una monarquía de tipo oriental logra nivelar por debajo al conjunto de los súbditos, acción muy provechosa para el déspota porque le permite cortar de raíz la amenaza aristocrática.

Entre los griegos y romanos acostumbrados a la pluralidad de la democracia y la república solo podía defenderse la vuelta de la monarquía y el despotismo utilizando la argucia política de la nostalgia de un pasado que nunca existió. Es así como Platón y Cicerón, que propugnan la vuelta de la monarquía en Grecia y Roma, proyectan el sueño mítico de una realeza sin leyes en la cual un soberano virtuoso (el Rey Filósofo, el Príncipe, el Emperador) gobierna en perfecta paz y justicia sin necesidad de someterse a códigos ni asambleas:

"Cuando Platón [Republica, 271a] evoca la vida que llevaban los hombres en los tiempos de Cronos: "La divinidad en persona era su pastor y quien presidía sus vidas", lo que aparece como nostalgia de un pasado mítico es en realidad el modelo para un futuro ideal. El mito va al encuentro de la utopía que ha contribuido a construir, y en la época siguiente -helenística e imperial- se va a buscar ese rey-pastor, mortal más grande que el resto, bajo el cual los hombres ya habían conocido, en la frontera de su memoria, una vida de seguridad y equidad." ${ }^{17}$

El gobernante es un Dios para sus criaturas, pero también un pastor para sus ovejas. Recobrada con el fin de someter al pueblo, la metáfora monárquica del rey pastor y el súbdito ovejuno es bien antigua. Entre las distintas formas de bestializar la imagen del gobernado, aquella que designa a los regidos como ovejas de una grey de animales sumisos enlaza con el paternalismo político. Los reyes babilonios ya se llaman a sí mismos pastores de su pueblo, y Homero utiliza el término "pastores de pueblos" (poiménes laon) para referirse a los

16 Hannah Arendt, ¿Qué es política?, Barcelona: Paidós, 1997, pág. 46.

17 Chantal Millon-Delsol, ob. cit., pág. 212. 
jefes y gobernantes. Jenofonte nos brinda la clave paternalista de la metáfora pecuaria: al recordar que Homero llama al rey Agamenón “pastor de pueblos”, pregunta el historiador griego: “¿No será porque, semejante a pastor que vela porque sus ovejas se hallen en buena salud y que tenga lo que les sea menester, debe velar un general para que sus soldados se conserven bien de salud, tengan todo lo que les hiciera falta y estén en condiciones de ser soldados?". ${ }^{8}$ El rey cuida de la buena salud y del bienestar material de sus súbditos del mismo modo que el padre cuida de sus hijos y el general de sus soldados.

Recobrar la dimensión gregaria o borreguil de la ciudadanía fue un expediente útil durante la época helenística, cuando se fue diluyendo el breve paréntesis democrático para volver al ideal de un Príncipe pacificador cuyos méritos lo elevan muy por encima del resto de los mortales. Este Príncipe justo rodeado de consejeros sabios que van a hacer de él un modelo de virtud en la expansiva Roma del Imperio, Augusto en primer lugar, supone una adaptación edulcorada de la temible figura del viejo Tirano oriental en el centro de su camarilla. En efecto, la palabra "Princeps" es un eufemismo porque en origen significaba algo tan corriente como primer jefe o persona principal. Este vocablo era tan inocente y tan útil porque radicaba muy lejos de las connotaciones teológicas de la palabra "Rex". Menos de treinta años después de su entronización, el monarca de hecho que gobernaba bajo el falso título de Príncipe, el emperador Augusto, se hizo otorgar otro título engañoso, el de Pater patriae o Padre de la nación. ${ }^{19}$ Los posteriores emperadores se harán llamar con el mismo título, y así el poeta Marcial versifica en su poema dedicado a Tito: "Suenan las voces de diferentes pueblos, pero solo hay una / cuando se dice que eres el verdadero padre de la patria”. ${ }^{20}$

Parecido fue en Grecia el proceso mistificador llevado a cabo por Platón. El régimen asambleario de la ekklesía democrática (horizontal, tentativa, entre "hermanos") va a pasar a ser considerado el reino de la mera dóxa, de las opiniones necias; en cambio el despotismo ilustrado que dibuja la República será el dominio paternal de la certera ciencia (epistéme) al alcance solo de un sabio, el Rey Filósofo que

18 Jenofonte, Recuerdos de Sócrates, Barcelona: Edicomunicación, 1986, pág. 92 19 Finley, M. I., Aspectos de la Antigüedad, Barcelona: Ariel, 1975, págs. 262 y 263.

20 Marcial, Libro de los espectáculos, “Al emperador”, 11-12. Traducción de Antonio Ramírez para la ed. Gredos (Epigramas I, Madrid, 2001). 
ejercerá las funciones de padre político. ${ }^{21} \mathrm{El}$ monarca despótico de épocas anteriores se convertirá por arte de ficción filosófica en el "rey esclarecido": fronimos basileus. ${ }^{22}$ Cicerón, por su parte, que había definido la familia como origen de la ciudad (principium urbis) y semillero del Estado (seminarium rei publicae), retomará la argucia del dictamen científico del sabio paternal para elogiar al pueblo sometido al veredicto de ese único hombre que le exime de la obligación de pensar a cambio de ofrecerle seguridad: "En lugar de plegarse a la voluntad del pueblo, se preocupa de su verdadero interés". ${ }^{33}$ Contra la falibilidad de las vanas opiniones de la democracia y la república se alza la infalibilidad de los decretos del despotismo y la monarquía. Claro que a la teoría justificativa de la monarquía esclarecida por el saber cierto o científico frente a la plebe infantiloide no le siguió la práctica de los buenos gobiernos: Séneca se encargó de la educación de Nerón con resultados poco memorables, y de los emperadores romanos pocos obraron más bien que mal, pero los hombres leídos siguieron haciéndose ilusiones con la inminente llegada del Príncipe blanco. Al final del siglo IV, con el Imperio a punto de desplomarse, Sinesio aún escribe: "El abismo nos rodea por todas partes [...] Solo un monarca esclarecido puede todavía salvarnos"24. Millon-Delsol concluye: "El rey esclarecido, filósofo o sabio, decididamente no existe. Se le espera de reino en reino: pero en vano. No es un hombre vivo, sino la buena conciencia de un pueblo. Lo mismo vale para el rey virtuoso". ${ }^{25}$

En esa adversaria monárquica de la democrática Grecia que fue Persia, el Rey ya figura como Padre del pueblo. El ideal del emperador, personificado en Ciro el Grande, aparece como padre prolífico de una gran familia, el Estado, de diferentes razas y lenguas que se disolverían o caerían en la guerra civil si él desapareciera. Como antes apunté, la nivelación despótica o paternalista de los súbditos se debe a que el tirano no tolera ninguna clase dirigente ni minoría de mérito a su lado. Si persiste alguna forma atenuada de aristocracia, queda sometida al poder de un soberano que cortará cualquier intento de someterlo a control. Todos los súbditos están igualados por bajo, como si fueran hijos de corta edad. La familia imperial solo admite

21 Chantal Millon-Delsol, ob. cit., págs. 213-214.

22 Platón, Político, $292 \mathrm{~d}$.

23 Cicerón, Sobre la República, cit. en Chantal Millon-Delsol, ob. cit., pág. 216, 24 Sinesio, Al emperador Arcadio, cit. en Chantal Millon-Delsol, ibidem, pág. 218. 25 Chantal Millon-Delsol, ob. cit., pág. 218. 
un hombre libre, que es el padre de la nación. ${ }^{26}$ El mito del rey-padre Ciro creado por Jenofonte proyecta en el emperador persa el ideal mitificado de Agesilas o Teleutias, otros reyes retratados por el mismo historiador como padres providentes y sacrificados. ${ }^{27}$ Tres milenios después, transformada Persia en Irán tras la influencia islámica, el faqih (Sabio en la Ley) o gobernante experto en derecho es como un padre que debe guiar a los súbditos a modo de niños que se han tornado huérfanos al crecer. En su tratado programático El Gobierno Islámico proclama el Líder Supremo de la Revolución Islámica, Ruhollah Jomeini:

"El gobierno del faqih es una cuestión racional y extrínseca, existe solamente como una clase de elección: como la elección de un tutor para un menor, para el gobierno de la provincia o para cualquier otro cargo. Respecto al deber y la posición no existe, de hecho, diferencia entre el guardián de una nación o el tutor de un menor. Es como si el Imam hubiera elegido a alguien para la custodia de un menor, para el gobierno de una provincia o para cualquier otro cargo". ${ }^{28}$

La monarquía tiende no solo a la santa mentira del dios-rey, sino también a la noble mentira del rey-padre, porque es el régimen de gobierno idóneo para ambas. Siguiendo el arquetipo medieval de la familia como modelo de la sociedad, el obispo inglés Roger Mainwaring mantuvo en el s. XVII que el rey está unido a su pueblo por un vínculo complejo que entrecruza los lazos de: a) el Creador y la criatura, b) el esposo y la esposa, c) el padre y el hijo, y d), el amo y el siervo. ${ }^{29}$ Este conglomerado familiar-político-religioso de la monarquía se observa mejor in absentia: cuando fenece la República romana, los escritores con memoria dicen que ha muerto la dignidad del pueblo porque la monarquía imperial que la va a suceder es un régimen oriental de servidumbre organizado por un solo señor. Antes del paréntesis grecorromano de gobierno compartido, en los pueblos históricos impera un regnum que implica la dominatio por parte de uno solo, el dominus o señor de la casa común. Con la caída de la república, vuelve a regir la cosa pública una potestad familiar y doméstica que, llevada al terreno social, dará en el jefe militar, en el dictador, en el rey oriental.

26 Ibidem, págs. $21 \mathrm{ss.}$

27 Ibidem, pág. 219.

28 Imam Ruhullah Musawi al Jomeini, El gobierno islámico, Bogotá: Biblioteca

Islámica Ahlul Bait, 2004 (<www.biab.org>, edición digital), pág. 62.

29 Roger Mainwaring, Religion and Allegiance, cit. en John N. Figgis, El derecho

divino de los reyes, México, D. F.: Fondo de Cultura Económica, 1942, pág. 122. 
Es la vuelta al origen, pues ya en la época hurrita (segundo milenio a. C.) encontramos que el tratamiento recíproco entre el señor y el vasallo era el de "padre" e "hijo".$^{30}$ Es el mismo despotismo familiar que pervive en Asia tras el periodo helenístico. Entre los edictos del rey Asoka, el monarca que unificó la India a la muerte de Alejandro Magno, leemos "Todos los hombres son mis hijos". Asoka ha tomado la palabra prestada de los clérigos, pues poco después añade en el mismo lugar: "Y obrando así, ganareis el cielo y seréis el pago de mi deuda" ${ }^{31}$ La invención de la santa paternidad con fines de mando atraviesa la historia, y los colonos europeos que despejaban el camino blanco hacia el Oeste norteamericano lo utilizaron al encontrarse de frente con los nativos ottowa de Louisiana. Ante un jefe indio que cerraba el paso a la expedición en el Missouri, el capitán William Clark le amedrentó con la existencia de un Padre del pueblo blanco superior al suyo: "Hemos sido enviados por nuestro Gran Padre, que podría en un momento exterminaros". ${ }^{2} \mathrm{~A}$ su vez, los rebeldes que hicieron nacer los Estados Unidos al ganar la guerra a sus compatriotas ingleses de la metrópoli se harán llamar Padres fundadores (Founding Fathers) de la nueva nación. Pero es que la noción de "padres de la Patria" ya fue expuesta en el mundo antiguo por Plutarco como una argucia de las clases rectoras para ocultar los verdaderos motivos de las grandes diferencias sociales. Plutarco especula con la posibilidad de que, a fin de apaciguar la envidia o la indignación de los menos favorecidos, Rómulo creó el Senado por el procedimiento de elegir "a los cien más nobles" y de llamarlos "patricios" (del latín patres, padres), pues "considerando justo que los principales y más influyentes debían cuidar con paternal preocupación y desvelo de los más humildes, y enseñando a los otros a no temer ni mirar con malos ojos las dignidades de los poderosos, sino a tratarlos con agrado, dándoles la consideración y el nombre de padres, así los llamó”. ${ }^{33}$ También para Cicerón el título de padres fue no tanto una concesión espontánea del pueblo cuan-

30 Elena Cassin, Jean Bottero y Jean Vercoutter, Historia universal. Los imperios del Antiguo Oriente, Madrid: Siglo XXI, 1977, pág. 163.

31 Asoka, Edictos de la ley sagrada, E. R. S. II, Barcelona: Apóstrofe, 2002, págs. 102 y 103 , respectivamente.

32 James K. Hosmer (ed.), History of the Expedition of Captains Lewis and Clark. 1804-1806, vol. I, Scituate, Massachusetts: Digital Scanning, Inc., 2002, pág. 89.

33 Plutarco, Rómulo, 13, 2 y 5. Trad. de Aureliano Pérez Jiménez para la ed. Gredos. 
to una elección meditada de la autoridad máxima, el rey. En Sobre la República describe Cicerón a los senadores como aquellos "a los que el mismo rey [Rómulo] había dado la facultad de llamarse solo 'padres". ${ }^{34}$ En realidad, los senadores eran simplemente los grandes propietarios de tierra, terratenientes a quienes desde antiguo se llamó patres en el sentido de patrones de unos arrendatarios a quienes alquilaban sus parcelas en tanto clientes (de cluere, acatar u obedecer) sujetos a su poder (clientes) o hasta esclavos de su propiedad. ${ }^{35}$ La elección del título de "padres" con la intención engañosa, pero políticamente útil, de aplacar la irritación por la diferencia de género de vida entre terratenientes y arrendatarios o temporeros persiste unas líneas más adelante, cuando Plutarco añade sobre los paternales patricios: "Y, efectivamente, todavía hoy, a los que pertenecen al Senado, los extranjeros los llamaron autoridades, y los propios romanos, patres conscripti, empleando el nombre que más prestigio y dignidad encierra y que inspira menos envidia". ${ }^{36} \mathrm{El}$ concepto de rey-padre del período helenístico e imperial romano también encierra un elemento de propaganda justificativa del poder despótico gracias a las bellas nociones de amor, desvelo y providencia. Séneca se lo aplica a Nerón sin importarle la crueldad de su ejecutoria. Millon-Delsol explica la deriva ideológica del término en el periodo postdemocrático imperial:

"Del principio al fin del Imperio, el príncipe es descrito como ese pastor que protege a su rebaño. Una idea de fraternidad humana, que el cristianismo naciente va a desarrollar, sostiene esta teoría: el rey es el padre, los súbditos son los hermanos. Todo un sistema de propaganda: monedas, edictos, escritos de pedagogos o de filósofos, afirma que el rey es un padre consagrado al bien común -a la utilitas publica-, presta a sacrificarlo todo por sus súbditos. "Desde hace tiempo ejerces de padre del Universo", escribe con énfasis Ovidio de Augusto, a quien compara con el dios Marte en su condición paternal presente y divina futura: "Padre Marte, y tú, Padre César; prestadle vuestro apoyo divino a su partida, ya que uno de vosotros es dios y otro lo será". Todo acto del emperador es un pretexto para elogiar su benevolencia paternal, su generosidad, su solícito celo. A la muerte de Pertinax, es un padre lo que el pueblo también ha perdido. A la muerte de Constantino, evoca Eusebio, el pueblo se disemina por las calles

34 Cicerón, Sobre la república, II, 11. Traducción de Álvaro D’Ors para la ed. Gredos.

35 Theodor Mommsen, Historia de Roma I, Barcelona: RBA, 2005, pág. 213.

36 Ibidem, 13, 6 . 
llorando, como si unos niños hubieran perdido a su padre. Haría falta un volumen para evocar los diversas loas, a cuál más ridícula, que colman a los emperadores de los beneficios de la propaganda." 37

Así como la falta del padre causa el infortunio del hijo, la única alternativa al mando gobernante es el limbo, el caos, la anarquía dejada de la mano de Dios. El argumento arcaico de autoridad en virtud del cual la sociedad no podría subsistir sin el respaldo del rey o del emperador no difiere del utilizado por las autoridades políticas y las religiones institucionales; se trata de la amenaza velada en virtud de la cual la deslealtad o desobediencia al gobernante implica el desplome de la sociedad entera, al modo en que las familias de sociedades tradicionales iban a la ruina cuando faltaba el progenitor. No bien el poder de la jefatura única queda confirmado por el cielo, toda resistencia resulta inicua.

Esta esclavitud en forma de minoría de edad del súbdito se extiende desde el origen de las civilizaciones hasta la aparición de la democracia en Grecia. La igualdad democrática de los ciudadanos griegos implica la libertad bajo el imperio de la ley votada por todos que los romanos de la república llamarán Libertas sub lege. En el curso del primer milenio antes de Cristo, las ciudades griegas del Mediterráneo occidental construyen una nueva organización política basada en la opinión de que las diferencias personales no son un obstáculo para el gobierno, como las concebía el déspota porque se resistían a su voluntad, sino, más bien al contrario, su mayor patrimonio político. Ese poder descentralizado bajo una ley dictada por el común se funda en la libre expresión de la pluralidad de opiniones, y no en la imposición de una voluntad única. ${ }^{38}$

Tras el experimento democrático grecorromano, el cristianismo auspició la vuelta de la vieja monarquía sacra, y corriendo el tiempo será Tomás de Aquino quien sistematice la visión política de la familia como una organización "monárquica". ${ }^{39}$ El Estado tomista medieval que luego recuperó Francisco Suárez con su Estado tutelar fue una suerte de organismo místico cuya cabeza estaba representada por "el padre que ejerce con plenitud la 'potestad dominativa' sobre sus súbditos".40

37 Chantal Millon-Delsol, ob. cit., págs. 220-221.

38 Chantal Millon-Delsol, ob. cit., págs. 16-17.

39 John N. Figgis, El derecho divino de los reyes, ed. cit., pág. 122.

40 Enrique Krauze, Redentores. Ideas y poder en América Latina, Barcelona:

Debate, 2011, pág. 512. 
La excusa paterna para apropiarse del fruto de la fuerza de trabajo del súbdito labrador funciona mejor si este es un esclavo. Entre las justificaciones para la explotación de los indígenas americanos por los invasores castellanos encontramos la de que aquellos son amentes o privados de razón (a-mentes), y, por tanto, necesitados de un padre llegado de fuera que los enderece. El hecho de que los indios se las hubieran arreglado por su cuenta antes de la llegada de un padre blanco que nunca los concibió ni crió no impediría a los colonizadores disfrutar del efecto tranquilizador de sus patrañas de amparo. Así como el padre trata a su hijo privado de razón, así los reyes de España deben tratar a los pobres indios sin ciencias ni artes liberales ni mecánicas. Francisco de Vitoria hila con oportunas razones:

"Puede, pues, alguno decir que para utilidad de ellos pueden los reyes de España tomar a su cargo la administración de aquellos bárbaros, y nombrar prefectos para sus ciudades, y gobernadores, y aun darles también nuevos señores si constara que esto era conveniente para ellos. Esto digo que puede ser legítimo, porque si todos eran amentes, no hay duda que esto sería, no solamente lícito, sino convenientísimo, y, es más estarían a ello obligados los príncipes, lo mismo que si se tratara puramente de niños."41

El derecho de tutela compartida por los poderes laico y eclesial brilla con todo su esplendor si los salvajes están desnudos, como criaturas recién venidas al mundo que es preciso vestir cuanto antes, pero sobre todo son los súbditos ya vestidos los que aquí nos interesan. En la católica Francia del siglo XVII, nos cuenta Étienne Thuau, el rey se define como père du peuple en una "religión de la obediencia" que deja al pueblo con la única función política de obéir sans murmurer. En la Inglaterra de ese mismo siglo, con la pérdida de poder del Papado y el paulatino descrédito del derecho divino, surge la figura sobresaliente de Robert Filmer, que desarrolla las posibilidades de concebir al rey como pater patriae, pero lo preceden también otros nombres como los de Juan Bodino o Griffith Williams, el obispo de Ossory, quien afirma en su Jura Magistratus: "Todo jefe de familia que gobierna su propia casa es un pequeño rey", y "un reino no es sino una gran familia en la que el rey tiene potestad paterna”. ${ }^{22}$ Más adelante, Robert Sanderson afirmará que el amo o paterfamilias es una

41 Francisco de Vitoria, De los títulos legítimos, 1539, en Marcel Merle y Roberto

Mesa (comps.), El anticolonialismo europeo, Madrid: Alianza, 1972, pág. 81. 42 John N. Figgis, ob. cit., pág. 123. 
especia de pequeño monarca, y que el poder del amo sobre el siervo viene a ser el del magistrado sobre sus súbditos; de tal forma, el magistrado es Pater Patriae, padre de la patria, en la medida en que el amo es Pater familias.

En esta línea de argumentación merece un apartado propio el escritor inglés Robert Filmer. Su Patriarca, publicado en 1680, mantiene que el poder de los reyes es natural porque se basa en la paternidad. En efecto, el derecho a gobernar a los hijos es a la vez natural y divino porque Dios lo impuso a través de Adán, el primer humano. Bebiendo siempre en la fuente de autoridad de la Biblia, Filmer defiende la plena legitimidad del actual poder soberano vigente en todos los estados monárquicos a partir del derecho natural del padre a gobernar a los hijos. Este derecho es el más antiguo de todos, pues se remonta al origen de la humanidad, allá en el Paraíso Terrenal. El derecho de naturaleza por excelencia es el paterno, y se conserva solo en los regímenes monárquicos legítimos. La explicación de este aserto nos lleva al corazón de la ingeniosa doctrina de Filmer, la cual parte de un hecho bíblico incontestable: Adán solo debía obediencia a Dios por ser la primera criatura del universo que Este creó, pero los hijos de Adán, que también nacieron ya sujetos (súbditos) a su padre natural, Adán, le debían asimismo obediencia a este último. Y no una obediencia cualquiera, sino tan absoluta como la de la criatura respecto a su Creador. Pues Adán es un monarca absoluto en tanto padre de sus hijos ("El padre de familia gobierna sin otra ley que su propia voluntad”). Así pues, Caín, Abel y Set eran súbditos de Adán porque la autoridad familiar del padre coincidía en aquellos primeros días con la autoridad política del rey. Siendo en aquel instante inaugural familia y sociedad la misma cosa, Adán fue el primer padre y a la vez el primer monarca de la humanidad.

Que hoy día todos los hombres nacen siervos (sujetos, súbditos) de su rey paternal es la consecuencia natural y querida por Dios de que Caín, Abel y Set fueran hijos y a la vez súbditos de Adán. Dios quiso que el gobierno legítimo sobre la tierra fuera monárquico precisamente al conceder a Adán el poder sobre las bestias y el dominio sobre sus hijos: "Dios, al hacer a toda la humanidad de un solo hombre, parece que abiertamente quiso indicar que aprobaba el gobierno de un solo hombre más bien que el de muchos". ${ }^{43}$ Los sucesores de las primeras generaciones en la monarquía familiar universal desde el

43 Robert Filmer, El Patriarca o el poder natural de los reyes, pág. 33, en Robert 
Diluvio Universal fueron los patriarcas descendientes de Noé, padres de familias copiosas y a la vez reyes que al morir fueron cediendo la autoridad a sus hijos primogénitos, convertidos a su vez en reyes legítimos de sus respectivos pueblos. En consecuencia, hoy día (siglo XVII) los reyes son, o bien padres de su pueblo, o bien herederos de dichos padres. Los reyes ilegítimos son simplemente usurpadores llegados de fuera que quieren romper la cadena sagrada de la dinastía para introducirse como una cuña de material heterogéneo o bastardo. El rey es, pues, siempre padre de su pueblo por vía de herencia. En la vieja hiedra que hermosea el muro de la nación, la santa mentira del gobernante divino se enreda en nudos inextricables con la noble mentira del gobernante paterno. Como la monarquía paterna es querida por Dios desde que impuso a Adán como primer patriarca, el poder real y el paternal son absolutos (los súbditos no tienen derecho a ninguna cuota de gobierno) y concordantes. Filmer explica así el origen de la necesaria sumisión política de los súbditos a sus señores naturales:

"No veo, pues, cómo los hijos de Adán o de cualquier otro hombre pueden estar libres de la subordinación a sus padres: y siendo esta sumisión de los hijos la fuente de la autoridad real por disposición del mismo Dios, se sigue que el poder civil no solo en términos generales es de divina institución, sino que también lo es en su asignación específica a los primeros padres [...] Este señorío que Adán, por propia autoridad, tenía sobre el mundo entero, y que por derecho de él disfrutaron los patriarcas, fue tan extenso y tan amplio como el dominio más absoluto de cualquier monarca desde la creación [...] Puede parecer absurdo mantener que actualmente los reyes son los padres de su pueblo, puesto que la experiencia muestra lo contrario. Es verdad que todos los reyes no son padres naturales de sus súbditos, pero todos ellos son (o como tales han de ser considerados) los más próximos sucesores de aquellos primeros progenitores que fueron en principio los padres naturales de todo el pueblo, y los herederos de sus derechos al ejercicio de la suprema jurisdicción."44

Así pues, el derecho del padre a gobernar a sus hijos constituye la base del derecho que tiene todo monarca a gobernar a sus súbditos de forma ilimitada y, llegado el caso, arbitraria. No es la voluntad del pueblo la que elige al rey, pues no hubo ningún pueblo para elegir a

Filmer / John Locke, El Patriarca o el poder natural de los reyes / Primer libro sobre el Gobierno, Madrid: Instituto de Estudios Políticos, 1966, págs. 1-95.

44 Ibidem, págs. 8-13. 
Adán como primer padre y monarca, sino que fue elegido por Dios mismo, el único ser existente antes de que existiera el primer humano. Es el rey, pues, como Adán en su día primeval, quien tiene derecho a elegir a su sucesor, y no ha de consultar para ello a Parlamento o asamblea alguna: "Todos estos principales caudillos y padres tienen poder de consentir en la unión y de conferir a quien quieran sus derechos paternos de autoridad soberana; y el que es así elegido no ostenta el poder como un donativo del pueblo, sino como una delegación de Dios, de quien recibe su carácter real de padre universal”. ${ }^{4}$ ¿Acaso recibieron el poder los patriarcas de sus propios hijos?, preguntará retóricamente Filmer más adelante. ${ }^{46}$ La exigible obediencia absoluta del hijo a su padre es la base del exigible acatamiento absoluto del súbdito a su rey.

Lo que hace simpático a Filmer es que no fue un cortesano que ambicionara cargos o pensiones de la Corona. Su Patriarca, o el poder natural de los reyes solo sería publicado cuarenta años después de redactado y veintisiete después de muerto su autor debido a que este no pretendía ganar el favor real sino solo la cordialidad de los amigos y parientes notables de su condado. El hecho de que su teoría se convirtiera, después de ser exhumada casi por casualidad, en la doctrina política de la monarquía inglesa durante los dos últimos reyes estuardos resulta una consecuencia contingente de la utilidad de sus postulados para la concepción absoluta del poder monárquico. ${ }^{47}$

La defensa que hace Filmer de la monarquía pretende mostrar que el rey ama a sus súbditos como el padre ama a sus vástagos: por voluntad divina y a la vez impulso natural. Este pasaje de amor idílico puede resultar particularmente impresionante; aun cuando ya sospechemos de algún truco dialéctico escondido y algún non sequitur oculto en la cadena lógica de enunciados de Filmer, el argumento del amor paternal es capaz de tocar por un momento nuestra coraza broquelada contra las infinitas triquiñuelas de la potestad:

"Como el padre sobre una familia, así el rey extiende su solicitud sobre muchas familias para preservar, alimentar, vestir, instruir y defender a toda la comunidad. Sus guerras y su paz, sus tribunales de justicia y todos sus actos de soberanía tienden solo a preservar y distribuir entre todos sus subordinados y padres de familia de rango

45 Ibidem, pág. 15.

46 Ibidem, págs. 17-18.

47 Rafael Gambra, "Estudio preliminar”, págs. XIII y XXIV, en Robert Filmer / John Locke, ob. cit., págs. VII-XLI. 
inferior, y entre los hijos de los mismos, sus derechos y privilegios, de modo que todos los deberes de un rey se resumen en una universal solicitud paternal hacia su pueblo."48

A despecho de nuestro espíritu crítico, estas palabras de Filmer bien podrían hacernos exclamar: iQué hermoso!, pues nos ayudan a comprender el importante papel que este antiquísimo paradigma del padre o la madre solícitos hacia sus retoños ha desempeñado en el sometimiento de la plebe.

La sugerente construcción de Filmer será pacientemente desmontada por su compatriota John Locke en el Primer libro sobre el gobierno. Locke acierta en sus páginas a relacionar el profundo deseo de los príncipes autoritarios de justificar la monarquía absoluta con el argumento fundamental del Patriarca según el cual "ningún hombre nace libre”. Pues es verdad que, de Adán abajo, nadie nació libre sino sometido a su padre. Pero ello no tiene consecuencia alguna para la vida política: "Tenemos que creerles por su sola palabra cuando nos dicen que todos hemos nacido esclavos y que hemos de continuar así; que no hay remedio para ello; que a un tiempo entramos en la vida y en la esclavitud y no podemos librarnos de esta mientras no salimos de aquella. Ni la Escritura ni la razón, estoy seguro, dice tal cosa en parte alguna”. En primer lugar, sostiene Locke, Filmer no explica por qué llama autoridad real a la autoridad paterna; por qué ese fantasmón dominante de la paternidad ${ }^{49}$ le da derecho a dominar como rey y no a actuar como simple padre. Filmer va de la realeza a la paternidad, pero pretende ir de la paternidad a la realeza. Y esta no se sigue de aquella. Tanto en la ley natural como en la positiva, cuando un hijo dependiente llega a la edad adulta queda libre de la tutela paterna. "Después de eso, padre e hijo son igualmente libres, lo mismo que tutor y pupilo, pasada la minoridad; ambos se hallan sometidos a la misma ley, sin que le quede al padre poder alguno sobre la vida, la libertad y los bienes de su hijos". ${ }^{\circ}$ Locke confuta a Filmer citando al teólogo Richard Hooker: "Los locos y los idiotas no se libran nunca de ser gobernados por sus padres". ${ }^{11}$ Para descubrir el non sequitur cometido por Filmer hay que recordar las consecuencias de la maduración natural. Los hombres sí han nacido libres, solo que necesitan

48 Robert Filmer, El Patriarca o el poder natural de los reyes, ed. cit., pág. 16.

49 Ibidem, pág. 105.

50 John Locke, Ensayo sobre el gobierno civil, Barcelona: Orbis, 1983, pág. 54.

51 Richard Hooker, Of the lawes of ecclesiastical politie, cit. en John Locke, Ensayo sobre el gobierno civil, ed. cit., 1983, pág. 54. 
llegar a la edad adulta para ejercer su libertad natural. Del mismo modo que dijo que todos los hombres nacen sometidos, Filmer también podría haber dicho con la misma sinrazón que nacen irracionales, puesto que en la primera niñez todavía no ejercen la razón. Locke remacha: "Hemos nacido, pues, libres de la misma manera que hemos nacido racionales, pero de momento no podemos ejercitar ni la libertad ni la razón. La edad, que nos trae la una, nos trae también la otra". ${ }^{2}$ Filmer habría podido evitar el error de la esclavitud natural si, llevado de su deseo de justificar en la Biblia el origen adánico de la autoridad política, se hubiera acordado de la existencia de Eva. "Dios dice Honra a tu padre y a tu madre; pero nuestro autor se contenta con la mitad y deja fuera por completo a tu madre, como poco útil para su propósito". ${ }^{33}$ En su Ensayo sobre el gobierno civil, Locke pondrá sal en la herida del axioma patriarcal al recordar cómo el Antiguo Testamento siempre exige a los hijos obediencia al padre y a la madre (Éxodo XX, 12, Levítico XIX 3 y XX, 9...): "El hecho de que la madre participe en ese poder habría hecho muy poco favor a la posición de quienes sostienen con tanto empeño el poder y la autoridad absolutos de la paternidad". ${ }^{44}$ Con la finalidad de justificar un tipo de gobierno histórico llevándolo al origen del mundo, Filmer asevera que la Biblia afirma algo que no afirma en lugar alguno: que Adán es rey y soberano. "Al cotejar estas pruebas y razones sacadas de la autoridad de la Escritura... Confieso que no puedo encontrar dónde están esas pruebas y razones a favor de la soberanía de Adán; fuera de la ya mencionada Honra a tu padre. ${ }^{55}$ Más adelante, Locke centra su crítica a la libérrima interpretación de las Escrituras que hace Filmer, o, mejor, a la pura invención de la soberanía de Adán que es la base de toda su teoría monárquica:

"Yo no veo cómo la creación de Adán, que no fue otra cosa sino el recibir el ser inmediatamente de la omnipotencia y de la mano de Dios, le dio soberanía sobre cosa alguna [...] yo no encuentro dificultad en suponer la libertad de la humanidad, aunque siempre he creído en la creación de Adán [...] y lo mismo fue creado, antes que él, el león, rey de los animales, por el mismo poder creador de Dios: y si el mero hecho de existir por tal poder otorga dominio sin más, nuestro autor

52 John Locke, Ensayo sobre el gobierno civil, ed. cit., pág. 55.

53 John Locke, Primer libro sobre el gobierno, ed. cit., pág. 106.

54 John Locke, Ensayo sobre el gobierno civil, ed. cit., pág. 51.

55 John Locke, Primer libro sobre el gobierno, ed. cit., pág. 112. 
concederá al león un título tan bueno como el suyo, e indudablemente más antiguo." 56

Locke afirma no entender que Adán fuera monarca del mundo aun antes de tener súbditos (es decir, aun antes de tener hijos). Filmer intenta salvar este escollo aduciendo que "aunque no puede haber gobierno de hecho hasta que no haya súbditos, sin embargo, por derecho de naturaleza, le correspondía a Adán ser gobernante de su posteridad; aunque no en acto, sí al menos en Estado”. Nuestro primer padre sería rey, por tanto, desde su creación; un rey, ciertamente, privado de súbditos, pero en disposición de tenerlos. Locke ironiza sobre una concesión que Dios solo podría haber comunicado a Adán después de que naciera Eva y pudiera darle un hijo. "Bonita manera de ser gobernante sin gobierno, padre sin hijos y rey sin súbditos". ${ }^{57}$ ¿Qué derecho de naturaleza es ese? Pues Dios, recuerda Locke, no dio al hombre autoridad ni soberanía sobre otros hombres, sino solo sobre los animales y vegetales. Son los ipsissima verba del Génesis: "Y Dios les bendijo y les dijo, sed fecundos y multiplicaos y llenad la tierra y subyugadla, y tened domino sobre los peces del mar y sobre las aves del aire y sobre toda cosa viviente que se mueva en la tierra" $(1,28)$. De este mandato tan claro deduce por su cuenta Filmer que Dios dio a Adán dominio sobre todas las criaturas incluyendo los otros hombres, es decir, sobre el mundo entero. ${ }^{58}$ Tal inferencia es simplemente gratuita. Dios en ningún momento hace a Adán soberano de sus congéneres, sea en acto o en potencia:

"En oposición, pues, a la doctrina de nuestro autor de que Adán era monarca del mundo, fundada en este pasaje, mostraré: $1^{\mathrm{o}}$, que por esta concesión (Gn, 1, 28), Dios no dio poder inmediato a Adán sobre los hombres, sobre sus hijos, sobre los de su misma especie, y, por consiguiente, no fue hecho por este privilegio gobernante ni monarca. $2^{\mathrm{O}}$ Que por esta concesión Dios no le dio dominio privado sobre las criaturas inferiores, sino un derecho en común con toda la humanidad; por consiguiente, tampoco era monarca basándose en la propiedad que le había dado." 59

Desvariando ya en la invención de dominios absolutos, añade Locke, sir Robert podría haber llevado su poder monárquico un poco más

56 Ibidem, pág. 116.

57 Ibídem, pág. 118.

58 Ibídem, pág. 124.

59 Ibidem, pág. 125 . 
lejos. Quizá los reyes de tan absoluto dominio pueden comerse a todos los seres vivos, incluyendo a los lectores de El Patriarca, pues tal es la conclusión de que Dios hiciera a toda la humanidad, y no solo al reino animal, esclava de Adán y sus hijos a partir del citado pasaje del Génesis. ${ }^{60}$ Filmer, por fin, olvida asimismo que cuando Dios exhorta en el Génesis a nuestros primeros padres: “Tened dominio...” está empleando el plural porque no solo se dirige a Adán, sino también a Eva. El gobierno resultante no sería una monarquía, sino más bien una diarquía. "¿No debería ella ser dueña del mundo, lo mismo que él señor?”. ${ }^{61}$

\section{John Locke resume así su confutación de Filmer:}

"Pero si la creación, que no dio otra cosa que el ser, no hizo a Adán príncipe de su posteridad; si Adán, en Génesis, 1, 28, no fue constituido señor de la humanidad ni se le dio ningún dominio privado con exclusión de sus hijos, sino solo un derecho y poder sobre la tierra y las criaturas inferiores en común con los hijos de los hombres [...], si los padres no adquieren por engendrar a sus hijos semejante poder sobre ellos; y si el mandato Honra a tu padre y a tu madre no lo da, sino solo impone un acatamiento a todos los padres por igual, sean súbditos o no y a la madre lo mismo que al padre; si todo esto es así [...], entonces el hombre tiene libertad natural."62

Aún tiene reservado Locke un último dardo, quizá el más agudo, contra la doctrina patriarcal de Filmer. Citando al propio aristócrata inglés, quien afirma que Adán era señor de sus hijos, y que sus hijos, bajo su dominio, tenían a su vez poder sobre sus propios hijos, Locke hace ver que la presunta soberanía ilimitada e indivisa derivada de la paternidad de Adán habría durado, como mucho, solo una generación. Pues, en cuanto nuestro primer padre tuvo nietos, la cosa se enredó hasta el absurdo. Partiendo de las palabras de Filmer, "Adán, como padre de sus hijos tiene un absoluto e ilimitado poder real sobre ellos, $y$, en virtud de esto, sobre aquellos a quienes engendraron, y así en todas las generaciones" ${ }^{\prime 3}$, Locke observa que los hijos de Adán llamados Caín y Set tienen a su vez poder paternal sobre sus propios hijos, es decir, un poder también absoluto e ilimitado. Así que son a la vez vasallos absolutos de su padre Adán, y señores absolutos de sus propios hijos. En consecuencia, resulta que Adán tiene toda la autoridad

60 Ibidem, pág. 129.

61 Ibidem, pág. 130.

62 Ibidem, pág. 170.

63 Robert Filmer, El Patriarca o el poder natural de los reyes, ed. cit., pág. 8. 
sobre los hijos de Caín y Set en tanto abuelo, patriarca y señor suyo, pero sus hijos Caín y Set tienen también toda la autoridad sobre sus propios hijos en tanto padres y señores suyos. Ahora bien, tal doble condición es lógicamente imposible. O una cosa, o la otra. Dado que dos absolutos contradictorios se repelen, no puede ser que los nietos de Adán le deban obediencia absoluta a su abuelo al mismo tiempo que a sus padres. ${ }^{64}$ Robert Filmer quiere escapar del contrasentido con un distingo sutil: "No”, afirma, "los hijos de Adán, sometidos a él, tenían poder sobre sus propios hijos, pero siempre con subordinación al primer padre”, a lo que Locke contesta:

"Buena distinción, y que suena muy bien; es una lástima que no signifique nada [...]. Concedo de buena gana que, supuesto el poder $a b-$ soluto de Adán sobre su posteridad, cualquiera de sus hijos puede recibir de él un poder delegado y, por consiguiente, subordinado, sobre una parte de los demás o sobre todos ellos; pero este no puede ser el poder de que aquí habla nuestro autor, y que no es un poder por delegación o comisión, sino el natural poder paternal que él supone que un padre tiene sobre sus hijos." ${ }^{5}$

En efecto, se trata del mero poder natural de sujeción entre padres e hijos. Es el único que admite la Biblia. Solo que Filmer se empeña en afirmar que ese poder es absoluto e ilimitado. Tal cosa que no consta en la Sagrada Escritura, pero tampoco en la naturaleza ni en la razón: tener el hijo un poder absoluto, ilimitado e ilimitable sobre sus propios hijos en subordinación a otro poder absoluto, ilimitado e ilimitable, el de su propio padre, es una formidable contradicción que se deriva de la infortunada mezcla de Familia y Estado. ${ }^{66}$

Miguel Catalán Universidad CEU Cardenal Herrera e-mail: <mcatalan@uch.ceu.es>

64 John Locke, Primer libro sobre el gobierno, ed. cit., pág. 172.

65 Ibídem, págs. 172-173.

66 Ibidem, pág. 174. 